\title{
Two-Mode Brokerage in Policy Networks
}

\begin{abstract}
Gould and Fernandez (1989) developed a widely used operationalization of brokerage for onemode networks. The basic idea of brokerage is that the central actor or 'broker' benefits from spanning the gap (or structural hole) between two disconnected parties. However, it is not always advantageous to limit the systems studied to only one mode. We develop an operationalization of two-mode brokerage in which we can classify the structures according the heterogeneity of the types of actors involved. We apply this conception to water policy networks in the San Joaquin-Sacramento River Delta in California where two-mode networks represent organizations participating in multiple policy institutions. The potential benefits of brokerage are high in these types of fragmented systems where multiple institutions and organizations are involved with policy decisions. Of particular interest is the role of collaborative institutions, which are hypothesized to broker the most heterogeneous structures. We use our two-mode version of brokerage to construct a scale of brokerage from most homogeneous to most heterogeneous. This scale lets us categorize both the role of these collaborative institutions as well as the importance of brokerage in the system overall.
\end{abstract}




\section{Introduction}

The brokerage role, where one node acts as a bridge, intermediary, or boundary spanner between two otherwise disconnected nodes or groups of nodes (thus forming a "chain" of three actors), is an important concept in social network analysis. Ronald Burt's theory of structural holes is premised on the idea that a brokering individual or organization can take advantage of the different resources and information they can access, which cannot be accessed by other, nonbrokering nodes (Burt 2001). Gould and Fernandez (1989) developed one of the most widely used definitions of brokerage, which categorizes brokerage chains into distinct roles based on the classification of the nodes into different groupings (usually a categorical vertex attribute). In an example from health policy in the United States, they show that brokerage roles are associated with greater reputations for influence over the policy process (Fernandez and Gould 1994). Thus brokers can benefit from their positions by gaining access to diverse resources and information and acquiring a better reputation among others in the network.

Here we extend this idea from one-mode networks, defined by a set of nodes and the edges that connect those nodes, to two-mode networks. A two-mode network is made up of two different sets of nodes (called modes), where ties only connect nodes of different sets (see section 1.2). Fernandez and Gould (1989) used a one-mode network (generated from a survey question), but explained that they could have used a two-mode network consisting of the organizations and different events the organizations co-attended. They did not use the two-mode approach because a) they chose to test hypotheses in which event participation was viewed as an attribute, and b) they argued that co-participation in events reflects only short-term goals 
(Fernandez and Gould 1994, pp 1467). Although they were far more interested in the first mode (organizations) than the second mode (events), in many other cases (including the one to be described) this choice is not so clear. The method developed in this paper permits the investigation of brokerage chains using the data on both modes.

The method developed in this paper permits the investigation of brokerage chains using the data on both modes. The theoretical importance of our two-mode version of brokerage relies on similar theoretical reasoning as other definitions of brokerage. The benefits of brokerage are higher when they include more diverse groups, which serve as non-redundant sources of information, ideas, and other resources. Keeping the full two-mode structure permits us to examine the diversity of both modes, and allows us to empirically characterize the types of brokerage chains expected to provide the greatest benefits.

We apply our two-mode version of brokerage to an empirical case of water policy networks, where brokerage is particularly relevant. A defining feature of water governance is institutional fragmentation, which occurs when different governing institutions have overlapping responsibility for policy issues that span administrative boundaries, or work independently on issues that are in reality interconnected—what Lubell (2013; see also Long 1958) calls an "ecology of games". Within each policy "institution" (which other researchers have called "policy processes" or "venues") multiple participating organizations make collective decisions about various issues. The existence of interdependent policy institutions creates a large potential for "institutional externalities" in which organizations making decisions in one policy institution fail to consider the costs and benefits imposed on others. Although we focus on water policy, institutional fragmentation is a major challenge in most other policy domains, and brokerage provides benefits by helping to coordinate diverse actors and institutions. 
This article focuses particularly on the idea of "institutional" brokerage, in which policy institutions emerge to forge connections between institutions that were otherwise fragmented. Brokering institutions helps alleviate fragmentation by providing opportunities to negotiate over the benefits and costs of coordinated decisions (Berkes 2002; Carlsson and Sandstrom 2008; Crona and Parker 2012; Manring 2007; Stovel and Shaw 2012) and share information across different types of boundaries. Since the 1990s, environmental policy has witnessed the evolution of a massive number of "collaborative" institutions, which seek to play exactly this brokering role (Ansell and Gash 2007; Hughes and Pincetl 2013; Leach et. al 2002). These institutions are designed specifically to take advantage of the potential benefits of a brokering position (Schneider et al 2003).

In the next section, we will discuss the general idea of brokerage as it has emerged from the sociological literature on networks, and explain how it is operationalized in the context of twomode networks. We then describe some specific hypotheses to be tested in our example of water policy institutions. The results section tests these hypotheses by means of descriptive statistics, Exponential Random Graph Models (hereafter ERGM or ERG model), and simulations from the ERG model.

\subsection{Brokerage in One-Mode Networks}

Mardsen defines brokerage as a process "by which intermediary actors [brokers] facilitate transactions between other actors lacking access to or trust in one another" (Marsden 1982, p202). Interest in studying brokerage exploded after Burt's claim that "social capital is created by a network in which people can broker connections between otherwise disconnected segments" (Burt 2001). In the organizations literature, this same role is referred to with a variety of terms 
from boundary spanners (Aldrich and Herker, 1977; Friedman and Podolny, 1992), bridging organizations (Brown, 1998, Hahn et. al., 2006), broker organization (Chaskin, 2001), and many others (Collins-Dogrul, 2012). These brokers can profit from increased exposure to different ideas, knowledge, or resources (Burt 2001), boosted reputations and influence (Heaney 2006), and monopolizing communication pathways (Chaskin 2001). However, these roles are not without costs and potential pitfalls; brokers are often taking the highest risks when working with disconnected parties that can be suspicious of others or even hostile (Stovel and Shaw 2012).

Gould and Fernandez added a group identity component to Marsden's definition, arguing that frequently in social systems, actors are organized along different criteria - institution type, membership, issue focus, etc - and therefore have different goals. They were interested in why organizations crossed these group boundaries to work together and whether this structural position was related to perceived influence over policy negotiations (as determined by other organizations in the network).

Figure 1 shows Gould and Fernandez's classifications of the five types of brokerage possible

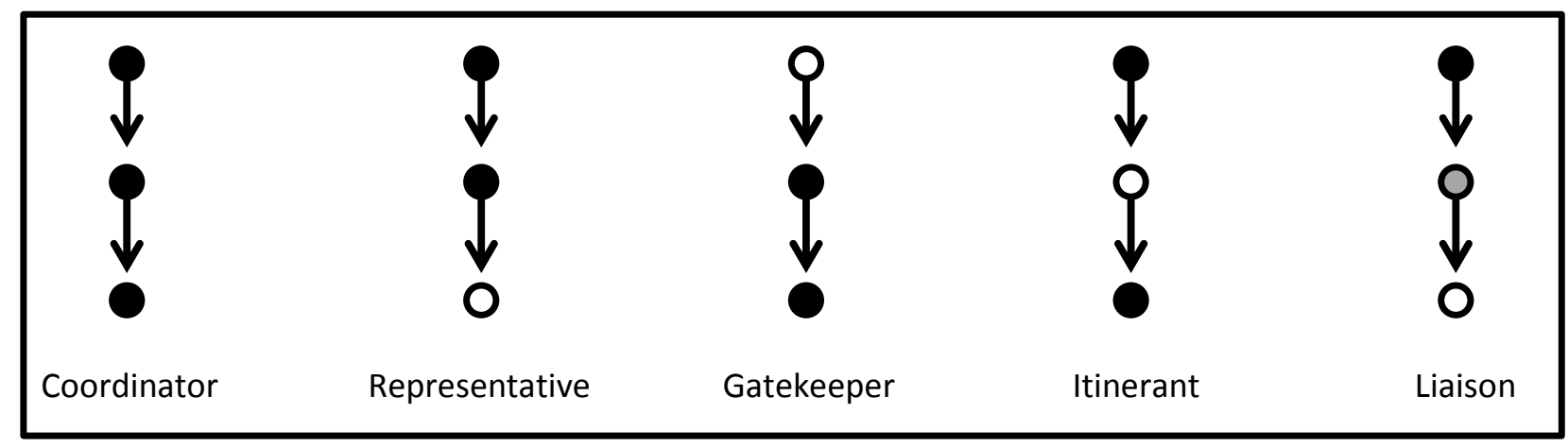

Figure 1: Gould and Fernandez' Brokerage Typology when group identity (as determined by a categorical attribute) is considered. The shading of the node, specifically black, gray, or white, indicates to which grouping the node belongs. The 
brokering organization is always the middle node in this "chain" - the one that both sends and receives a tie. The brokerage chain on the far left displays a scenario in which brokerage is occurring within one defined group or type of actors (indicated by the fact that all of the nodes are shaded black). In this condition, the broker is coordinating the activities of group members who have similar interests, aims, and goals. For the Representative structure, the broker represents his or her group to a member of a different group. This is indicated by the fact that the broker and the top node are both shaded the same, and the recipient of the broker's information (the node on the bottom) is shaded differently. In the Gatekeeper scenario, the flow of information is reversed - the broker receives information from a node in a different group (the white node at the top) and transmits the information to a node in the same group as the broker. The Itinerant structure occurs when the two alters (top and bottom) are from the same set of nodes (both shaded black) but the broker is from a different group. Finally, in the Liaison structure, is a case where all three nodes in the brokerage chain are from different groups.

One of Fernandez and Gould's main findings is that the benefits of brokerage are mediated both by the type of organization (the node sets) and the type of brokerage chain (the classification in Figure 1). The first distinction Fernandez and Gould make is between the individuals playing roles in the coordinator scenario and the other brokerage structures; because the coordinators broker only within their own type this is referred to as a 'null' form of brokerage (Fernandez and Gould 1994, p1459). The second distinction they make is by considering coordinator, representative, and gatekeeper brokerage roles as distinct from itinerant and liaison roles. They called the first three "insider" roles because at least one other actor in the chain is from the same subgroup as the broker, whereas the itinerant and liaison chains are "outsider" since the broker is the only representative of its type in the chain. In their health 
policy example, Fernandez and Gould use this insider/outsider division with the classification of organizations as government/non-government to posit a differentiated relationship between brokerage roles and influence. Although non-governmental organizations were found to have more influence when they held any type of brokerage position (Table 3, p1471), governmental organizations gained influence only when they held "outsider" brokerage roles in itinerant and liaison chains (Table 4, p1472). Fernandez and Gould (1989) argued that this results from the constraint that governmental organizations must be perceived as impartial in order to benefit from a brokerage position, but that is not the case for non-governmental organizations.

\subsection{Extending Brokerage to Two-Mode Networks}

A two-mode network has two sets of vertices, referred to here as $M$ and $N$, and each edge has two endpoints, $\left\{v_{1}, v_{2}\right\}$, such that $v_{1} \in M$ and $v_{2} \in N$. In the standard definition of two-mode networks, a vertex is never directly linked to another vertex from the same subset (although some work in multilevel networks uses an alternative; see Wang, Robins et al. 2013). Researchers have been studying two-mode network structures for almost as long as they have studied networks themselves (see Freeman's 2004 description of Hobson's 1884 study). Recently, there has been increased attention on the analysis tools used for two-mode networks (see a special issue in the Journal of Social Networks: Agneessens and Everett 2013). Many approaches to analyzing two mode networks consist of converting the data to a one-mode network (either MxM or $\mathrm{NxN}$ ) that is a projection of the original data. However, previous studies have shown that one-mode projections subvert many of the reasons for collecting the two-mode data structures in the first place, lose information, and can present misleading results (Borgatti and Everett 1997; Jasny 2012; Latapy et al. 2008; Opsahl 2011). 
Our two-mode expansion of Gould and Fernandez' brokerage categories is shown in Figure 2. The circles and squares represent different modes. Each category from Gould and Fernandez' typology is expanded to consider whether the nodes in the second mode, the squares, are from

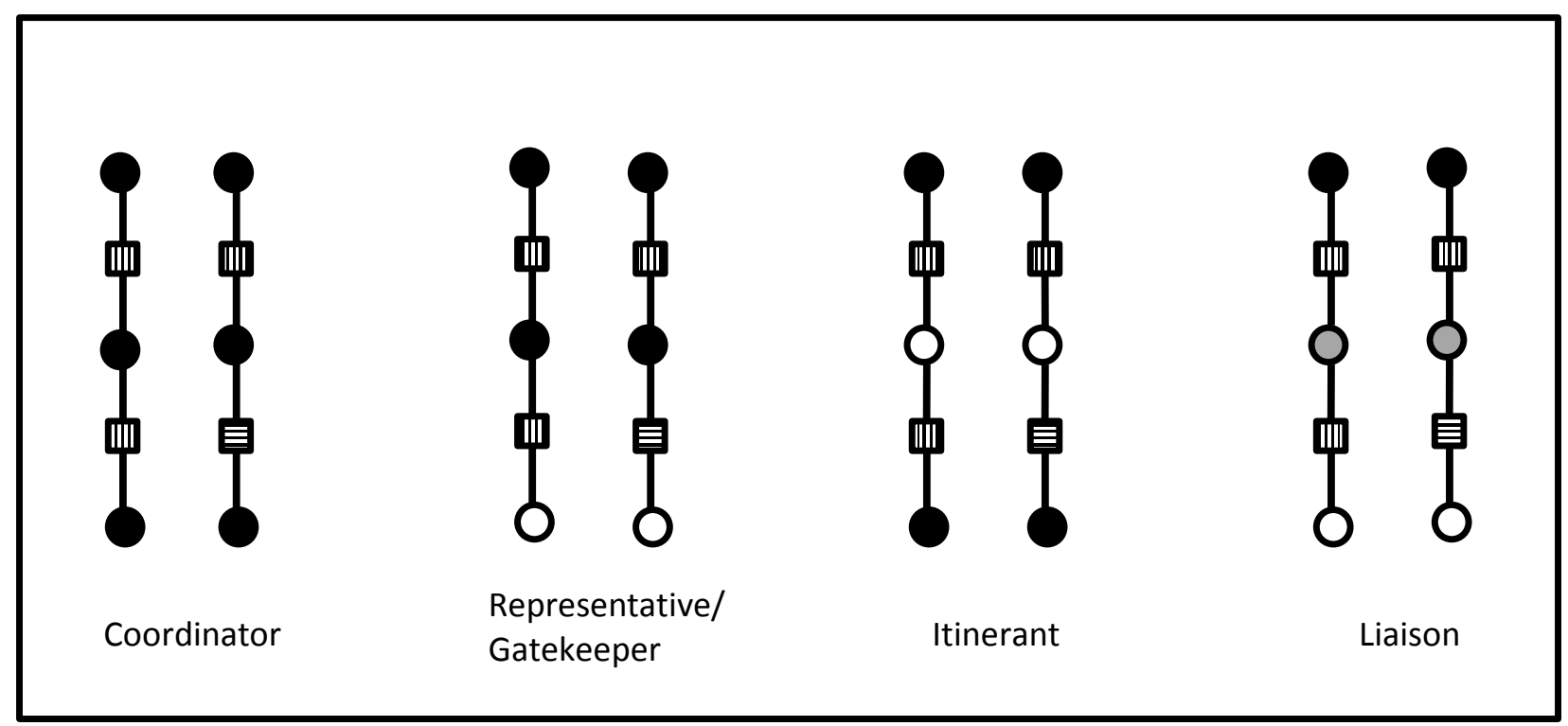

Figure 2: Two-Mode Brokerage Typology

the same attribute category or not (vertical vs. horizontal lines within the square). ${ }^{1}$ The onemode projection of these structures would result in the Gould and Fernandez categories but without directionality in the ties. We select institutions as the first mode (circles) and organizations (squares) as the second mode because we will develop specific hypotheses about the capacity of different institutional types to broker among other institutions via joint participation of actors (see section 2). Keeping the organizations permits the additional classification according to heterogeneity in that mode as well.

\footnotetext{
${ }^{1}$ Another difference is that these two-mode structures are undirected. While we could have a scenario in which one mode sends a tie to the other mode, the direction does not change the possible structural configurations as it can in the one-mode system. Representative and Gatekeeper brokerage, as conceived by Gould and Fernandez, have the exact same attribute configuration but differ in the direction of the ties. In our two mode interpretation, these categories are collapsed.
} 
The underlying theoretical perspective, that brokers receive some type of benefits from their position in the network, still applies in a two-mode network. Potential benefits include access to resources, reinforcement of reputation, learning new information, and controlling information flow between groups. The brokering institutions become venues where organizations know they will participate with organizations of differing perspectives and experience as evidenced by their participation in the other, disconnected institutions. These benefits depend on the attraction of different kinds of organizations with knowledge and resources gained from attending different kinds of institutions. When the two institutions at the ends of the brokerage chain are making conflicting decisions - the classic symptom of fragmentation - the brokering institution can help actors reduce the costs of conflict. Where Fernandez and Gould saw differences between homogeneous (coordinator) brokerage and increasing amounts of heterogeneity in the node sets, we can formalize this observation into an ordered scale of heterogeneity utilizing the two-mode structure.

\subsection{Homogenous and Heterogeneous brokerage chains}

To order the brokerage chains, we use a similarity index similar to the Simpson or Herfindahl index (Butts 2011; Simpson 1949; see Freeman 1978 for related ideas in a social networks context).

$$
\begin{gathered}
S\left(v_{i}\right)=\frac{\sum_{j \neq i}^{n} I\left(v_{i}, v_{j}\right)^{2}}{n-1} \\
\text { where } I\left(v_{i}, v_{j}\right)=\left\{\begin{array}{c}
1 \text { if } \operatorname{Attr}\left(v_{i}\right)=\operatorname{Attr}\left(v_{j}\right) \\
0 \text { otherwise }
\end{array}\right.
\end{gathered}
$$

$n$ is the total number of vertices (institutions or organizations) in whichever mode $v_{i}$ belongs to. 
Figure 3 shows a single brokerage chain labeled to match equations 3-6. Equations 3-6 are the specific versions of equation 1 for the brokerage case. For brokerage chains, the number of

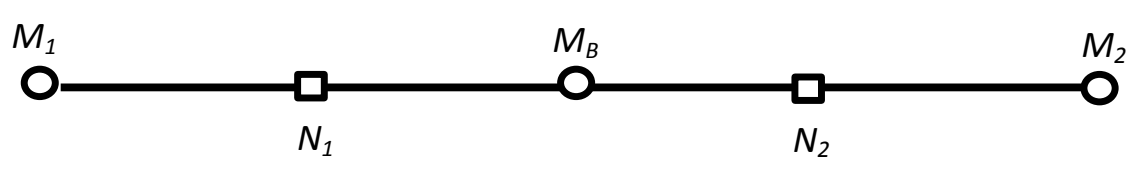

Figure 3: A single brokerage chain

institutions (mode 1) is always 3 and the number of organizations (mode 2) is 2.

$S\left(M_{B}\right)$ is calculated from the perspective of the broker, and $S\left(M_{i}\right)$ from the perspective of the two pendant institutions (labeled $M_{l}$ and $M_{2}$ in Figure 3). $S\left(M_{l}\right)$ is calculated as the probability that, randomly selecting another institution from the options of the Broker $\left(M_{B}\right)$ and the other institution $\left(M_{2}\right)$, that institution will have the same attribute group as $M_{1} . S\left(M_{2}\right)$ is calculated similarly.

$$
\begin{aligned}
& S\left(M_{B}\right)=\frac{I\left(M_{B}, M_{1}\right)^{2}+I\left(M_{B}, M_{2}\right)^{2}}{2} \\
& S\left(M_{1}\right)=\frac{I\left(M_{1}, M_{B}\right)^{2}+I\left(M_{1}, M_{2}\right)^{2}}{2} \\
& S\left(M_{2}\right)=\frac{I\left(M_{2}, M_{B}\right)^{2}+I\left(M_{2}, M_{1}\right)^{2}}{2}
\end{aligned}
$$

Each brokerage chain has two organizations (squares) labeled $N_{1}$ and $N_{2}$. Since the identity function $I$ is commutative such that $I(\mathrm{i}, \mathrm{j})=I(\mathrm{i}, \mathrm{j})$, it makes no difference whether we calculate $S(N)$ from the perspective of organization 1 or 2 . Thus $S(N)$ distinguishes between chains that have two organizations of the same type or of different types.

$$
S(N)=S\left(N_{1}\right)=S\left(N_{2}\right)=I\left(N_{1}, N_{2}\right)^{2}
$$


Using these indices, we can now order all the brokerage forms along a continuum from entirely homogenous, where the chain has three of the same type of node from the first mode and

$$
2^{\text {nd }} \text { Mode }
$$

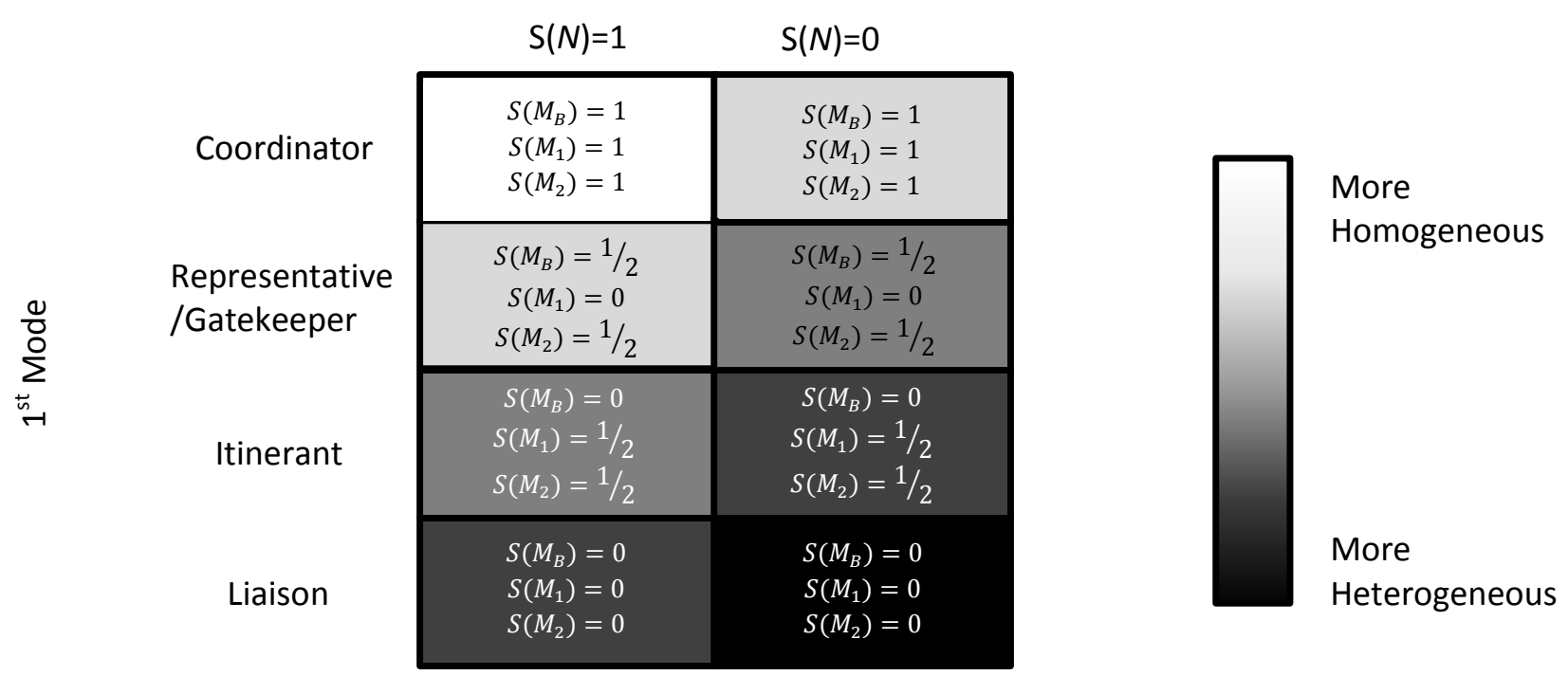

Figure 4: Organizing Brokerage Forms by Heterogeneity

two of the same type from the second, to heterogeneous with three different types of nodes from the first mode and two different types from the second. Our representation of this ordering is shown in Figure 4. The horizontal dimension differentiates between homogeneity and heterogeneity in the second mode according to the $S(N)$ value. The vertical dimension sorts differences in the first mode by first ranking according to the $S\left(M_{B}\right)$ score and then the sum of $S\left(M_{1}\right)$ and $S\left(M_{2}\right)$. Although the Representative/Gatekeeper and Itinerant categories both contain two of one kind of institution and one of another (in the first mode), from the perspective of the broker, the Representative/Gatekeeper structure is considered more homogenous because the broker belongs to the dominant subgroup. Ordering the scores first from the perspective of the broker and second from the perspective of the other institutions in the chain is consistent with Fernandez and Gould's findings that the similarities in brokerage patterns were due to the 
distinction of whether the broker was "inside" meaning had other members of its group in the chain (as in coordinator, representative, and gatekeeper chains) or "outside" where the broker was the lone representative of its group (Fernandez and Gould 1994).

This scaling of brokerage chains by levels of similarity expands on an observation Fernandez and Gould made that the types of brokerage tend to cluster by vertex type. In their study, organizations tended to participate in either coordinator, representative, and gatekeeper brokerage chains or in itinerant and liaison chains. From our standpoint, this can be redefined into two groups of brokers: one that brokers more homogenous sets of participants and one that brokers more heterogeneous chains. We see the brokerage chains at the two ends of this homogeneity/heterogeneity spectrum serving fundamentally different functions. Coordinator brokers position themselves among institutions with similar interests. Thus as a broker they are reinforcing connections between disconnected, but alike, others. As heterogeneity is introduced (and increases), the barriers to joint effort increase as well as the hypothesized rewards. An institution that brokers highly diversified groups of other institutions (and organizations) are faced with very different challenges. We therefore expect different types of organizations to participate in different types of chains. Unlike Fernandez and Gould's binary division of insider and outsider brokerage, we expect participation brokerage to follow an ordered scale.

\section{Hypotheses for Environmental Governance and Collaborative Institutions}

We perform an empirical analysis of two-mode brokerage in an environmental governance setting where institutional brokerage is expected to have substantial benefits. Specifically, we examine the complex institutional system of water governance in the California Delta. This complex institutional system is an "ecology of games" where a diverse community of policy 
actors participates in multiple institutions to make decisions about sets of interconnected water issues (Lund 2010; Lubell 2015; Lubell et al., 2014). These multiple institutions are fragmented, with a high potential for decisions made in one institution to have negative or positive effects on other parts of the system (institutional externalities). Multiple actors within the system have diverse policy preferences and information resources, which must be negotiated throughout the policy-process. Brokering institutions therefore play an important role in this context by facilitating coordination and information sharing among otherwise fragmented decisions, and negotiation among diverse actors. As a result, we theorize that the benefits of brokering are higher when the actors or institutions are heterogeneous.

In many cases, specific types of institutions called "collaborative partnerships" have emerged to fill this brokering role; these collaborative partnerships have been a central focus of the public and environmental policy literature in the last two decades (Sabatier et al. 2005; Ansell and Gash, 2008; O'Leary 2006). We posit the following three hypotheses based on the role of collaborative institutions in the ecology of governance games:

\section{H1: Collaborative partnership institutions are associated with the highest levels of brokerage.}

H2: Brokerage is concentrated among the most heterogeneous brokerage chains.

H3: Institutional brokerage structures exist in the network that are more than an by-product of lower level processes.

All of these hypotheses relate to the overall structure of policy networks under the assumption that brokerage evolves to capture the benefits of reducing fragmentation. Although these benefits are clear for environmental governance, the argument will be relevant to any other 
policy system where multiple policy institutions, issues, and actors create a fragmented ecology of games. The rest of this section develops these hypotheses in more detail.

The first hypothesis argues that that collaborative policy institutions are more likely to play brokerage roles than other types of institutions. Collaborative institutions are explicitly designed to bring otherwise disconnected institutions together by inviting participation from stakeholders who are involved with multiple policy processes and issues (Hughes and Pincetl 2012). If collaborative institutions do play their hypothesized brokerage role, they should be associated with a larger number of brokerage chains compared to other types of institutions (our schema includes 10 different types of institutions, see section 3.1). We examine descriptive statistics and use simulations from an ERG model to establish whether the observed number of brokerage chains associated with collaborative institutions is higher than expected from different null models of random graphs. This method allows us to examine the number of brokerage chains while conditioning on the fact that some types of institutions are generally more popular (well attended) than others. More popular institutions might have more brokerage opportunities (especially in sparse networks with low clustering) solely because they have more links in general. While popularity (degree) is not directly linked to brokerage, being able to control for it with density terms for each specific institutional allows us to identify brokerage chains that are not just a by-product of high degree nodes. We fit an ERG model to the data and simulate 1000 networks from that model to create a reference distribution. By comparing our empirical statistics to the same derived from the reference distribution, we can determine whether multistakeholder partnerships participate in more brokerage chains than expected given the sufficient statistics used as input for the ERGM. 
Hypothesis 2 states that if brokerage operates as assumed, the combined costs of playing any brokerage role coupled with the increased returns from brokering a heterogeneous chain should result in observing more heterogeneous chains. Additionally, since collaborative institutions were supposedly a response to the fragmentation that resulted from the lack of communication between different types of groups (Hughes and Pincetl 2013), we expect that the majority of brokerage opportunities would be between but not within groups. This finding would be consistent with Fernandez and Gould's similar observation that itinerant and liaison chains comprised the majority of the brokerage structures (Fernandez and Gould 1994).

Hypothesis 3 argues that brokerage is a distinct network process providing benefits over and above other structural network properties. The relevance of hypotheses 1 and 2 depends on this broader hypothesis. A necessary but not sufficient condition for this argument is to show that brokerage chains are not the result of more localized processes. For example, Bernoulli graphs (networks where each tie has the same probability of occurring) can contain brokerage structures generated at random. Gould and Fernandez showed that brokerage structures in observed networks were significantly more frequent than in Bernoulli graphs; this is evidence for the existence of brokerage as a distinct network process.

We extend this thinking to more complex baseline models than the Bernoulli graph, which are dissimilar to most real-world networks (Newman 2002; Robins et al. 2007). To better understand brokerage, we follow the same logic as Gould and Fernandez but use baseline models that contain networks that incorporate mechanisms we believe to be operating in addition to brokerage. For example, Lubell et al. (2015) find evidence of centralization and closure in twomode networks. Brokerage chains could emerge purely as a consequence of these more general structural processes. Such local processes may provide additional benefits to institutions; 
centralization can be interpreted as facilitating diffusion of information while closure helps build cooperation (Burt 2001; Lubell et al 2011; Scholz et al 2008). We argue that brokerage, by linking different types of institutions and actors, provides additional benefits over and above these more basic processes.

By simulating from models conditioned on the tendency of the empirical network towards centralization and clustering, we will test whether brokerage is simply the result of random combinations of lower-order graph structures. We will compare our data to networks simulated by two-mode ERG models that include these lower order structures. We then count the brokerage chains that exist in our empirical data, and check to see if the observed data has more "extreme" amounts of brokerage than predicted by models that include only the lower-level structures. If this hypothesis is true, it supports the idea that brokerage structures serve a unique function within the network over and above more commonly studied policy network structures like centralization and closure.

\section{Empirical Analysis of Water Governance Networks}

In this section we first describe how we created the empirical water policy networks focused on the San Joaquin-Sacramento River Delta in California (hereafter, CA Delta). The California Delta is the most important water policy context in California, and supplies water for a large portion of urban and agricultural needs in the state (Lubell et al., 2013). Following the data description is an elaboration of the methods. We use two-mode ERG models to establish baseline network models, and compare the average number of brokerage chains in simulated ensembles of networks to the observed data.

\subsection{Data Collection}


We populated the vertex sets for institutions and participating organizations through a newspaper and web search. We bounded the sample region to the legally defined California delta. Some additional areas were included because they might have impact within the delta; these areas include towns close to, but outside, the legal Delta boundary, and the Metropolitan areas in Southern California (primarily Los Angeles and San Diego). Only one newspaper is chosen per town. Exceptions may be made for papers based in a town, but reporting on the greater area, as well as large Metropolitan areas. Some areas may not have a paper (or at least is not listed in Newsbank), but may be covered under the umbrella of another paper. In cases where multiple newspapers exist in a locality, preference is given to the larger paper. We then searched the database for articles within the date range of 2005-2010 that included one or more of the following terms: water supply, water quality, flood, habitat protection, land use, and climate change. All mentions of institutions and organizations were added as nodes in the network. A tie was added to the network when an article or website listed an organization as participating in a given institution.

The data set consists of 146 institutions categorized into 10 types following the typology in Lubell et al (2011): collaborative partnerships, projects, local planning, conservancy, science, interest groups, joint powers, advisory committees, regulatory/permitting, and other. Our sample of organizations originally consisted of 1594 different entries but this was reduced to 527 (see section 3.2) with 14 separate types: federal government, state government, regional government, local government, water infrastructure special district, environmental special district, environmental group, trade/business/industry group, education/consulting/research group, multistakeholder coalition, political party, recreational group, agriculture, tribal group, and other. While some organizations clearly identified strongly with specific institutions (for example the 
Multistakeholder Coalition organizations were frequently participants in the Multistakeholder Partnership institutions), we were able to distinguish between organizations and institutions clearly due to the bipartite structure of a two mode network; only organizations could attend events held by institutions as opposed to other organizations. This distinction permitted clear categorization of what was an organization and what was an institution.

\subsection{Boundary Specification and Data Reduction}

Boundary issues are a common problem in network science (Doreian and Woodard 1994; Kossinets 2006; Robins et al. 2004). As with most other surveys of social networks from second hand materials, we cannot claim to have captured every institution or organization active during the study period, but we are fairly confident that we have captured the core organizations and institutions. The core is more easily captured since they will be mentioned more often. In capturing the core institutions, we also gathered information on many organizations that were only mentioned once. These organizations are 'pendants' in social network terminology. Since we are interested in how institutions (our first mode), broker other institutions via co-attendance of organizations (our second mode), pendant organizations cannot affect the statistic of interest. In each brokerage chain every organization is tied to two institutions; adding or removing the $2^{\text {nd }}$ mode (organization) pendants cannot alter the brokerage scores. Removing these pendants has added benefits; by reducing the $2^{\text {nd }}$ mode from 1594 actors to 527, the subsequent models are much more easily fit. To measure some of the impact of removing the $2^{\text {nd }}$ mode pendants, we introduce a continuous attribute for the first mode venues that represents the number of actors $\left(2^{\text {nd }}\right.$ mode) ties removed in the reduced network. By adding a density parameter for this attribute, we can determine whether the venues whose degree is substantially lowered by 
removing the border pendants subsequently have lower degree on average when compared with venues that lost fewer pendants (see Log(Pendant Number) in Table 2).

\section{Counting Brokerage Chains}

To address our hypotheses, we first count the number of brokerage chains found in our empirical network and classify them by the type of chain (according to the typology in Figure 2). A two-mode brokerage chain occurs whenever two institutions are separated by a shortest path containing three intervening nodes (two organizations and the brokering institution) and thus four ties. The left-hand side of Figure 5 is an example of a brokerage chain. By looking at the

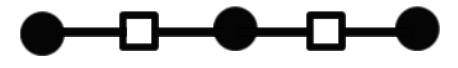

Chain with Brokerage

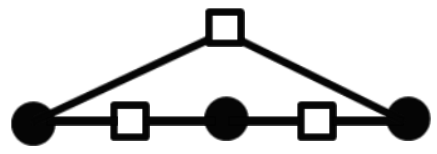

Chain without Brokerage

Figure 5: Finding Brokered Chains

chains with a shortest path length of four between the two institutions we discount any nonbrokered chains. A non-brokered chain is depicted on the right-hand side of Figure 5. This structure is not brokered since in this chain any two institutions can bypass the third and are connected by a shortest path of length two.

The counts of brokerage chains can distinguish between the institutions that do the most brokering compared to other institutions (Hypothesis 1), and whether the counts of the chains grow with level of heterogeneity (Hypothesis 2). However, we are also interested in whether the 
levels of brokerage in general are greater than we would expect (Hypothesis 3). To understand what we would expect under 'random' conditions, we turn to Exponential Random Graph Models (Robins, Pattison, et al. 2007).

\subsection{Exponential Random Graph Models (ERGM)}

Counting and classifying the number of brokerage chains cannot solely demonstrate what kinds of mechanisms might produce networks with these properties. Even Bernoulli random graphs, where each tie has an equal probability of existing and are thus formed "at random," can exhibit brokerage structures. In this analysis, we test whether the empirical number of brokerage chains could be explained by alternative mechanisms of network formation. Additionally, we will show that certain institutions are disproportionately occupying these roles. Following Wang et al. (2009) and Wang, Pattison, et al (2013), we consider a series of nested Exponential Random Graph models with increasing complexity.

The most basic baseline model is a Bernoulli model which uses one sufficient statistic - the number of edges in the model. We include additional terms for each category of organization and institution to reflect our belief that certain types of institutions and organizations will be more active than others. The coefficients of this model, one for each type of institution or organization (minus a reference category for each mode), indicate whether institutions or organizations of a particular type have more ties than we would expect due simply to the distribution of types in the network. As in Lubell et al. (2011), the reference categories are collaborative partnership institutions ( $1^{\text {st }}$ mode $)$ and local government organizations $\left(2^{\text {nd }}\right.$ mode $)$. Depictions of these terms are shown in Figure 6. 


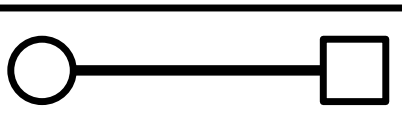

Overall density parameter

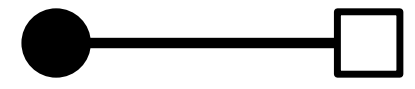

Density parameter for a specific Institution type

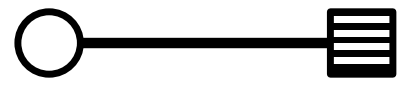

Density parameter for a specific

Organization type

Figure 6: Density Parameters

A model with solely density terms is still a dyadic-independent meaning that the likelihood of an edge is not conditional on the presence or absence of any other edges. However, this independence is not consistent with observations from the field (Lubell and Lippert 2011) nor with similar studies of organizational networks (Robins, Snijders, et al 2007). The premise of our argument is that which organizations attend which institutional venues is not decided in a vacuum but influenced by choices made by other institutions and organizations. We therefore investigate whether dyadic-dependent structures beside brokerage could explain the empirical brokerage structures that we observe. The following two Figures, 7 and 8, show two such structural tendencies that can be estimated in the ERGM framework: centralization and clustering. 
The degree dispersion parameters (Figure 7) measure the extent to which having ties already increases the likelihood of gaining additional ties. These parameters can be interpreted as measures of the tendency for centralization in the network (Robins, Snijders, et al. 2007). In contrast to the density terms, where each additional tie has the same probability of occurring as the previous tie, these terms reflect the tendency towards degree centralization in the network. These degree terms include a damping parameter - meaning that additional ties yield diminishing returns, and an alternating sign (even numbered stars give a positive boost where odd numbered stars decrease the likelihood of ties). These two qualities were added for computational and model-fitting benefits, and are discussed in Snijders et al. (2006). Since we are analyzing bipartite networks, we will include separate terms for degree dispersion in the first and second modes. The institutions and organizations may have different centralization mechanisms and therefore should not be combined as one parameter (Wang et al. 2009).

The final set of terms used in the more complex models is the shared partner terms shown in Figure 8. Where the degree dispersion terms measured centralization, the shared partner terms

\section{Degree Dispersion Parameters}

(Alternating Stars)

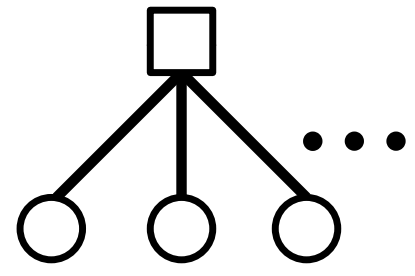

For Institutions

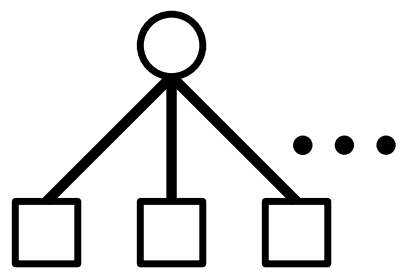

For Organizations

Figure 7: Degree Dispersion Parameters

measure a tendency towards clustering (Robins, Snijders, et al. 2007). As a pair of institutions 
(or organizations) is linked to a third institution (organization) through ties to the same actor in the other mode, they are more likely to be linked to increasing numbers of such institutions (organizations). As with the degree dispersion parameters, these terms are alternating and have a dampening coefficient to aid in model fitting and convergence (Snijders et al. 2006). Again, we separate these terms for the first and second modes.

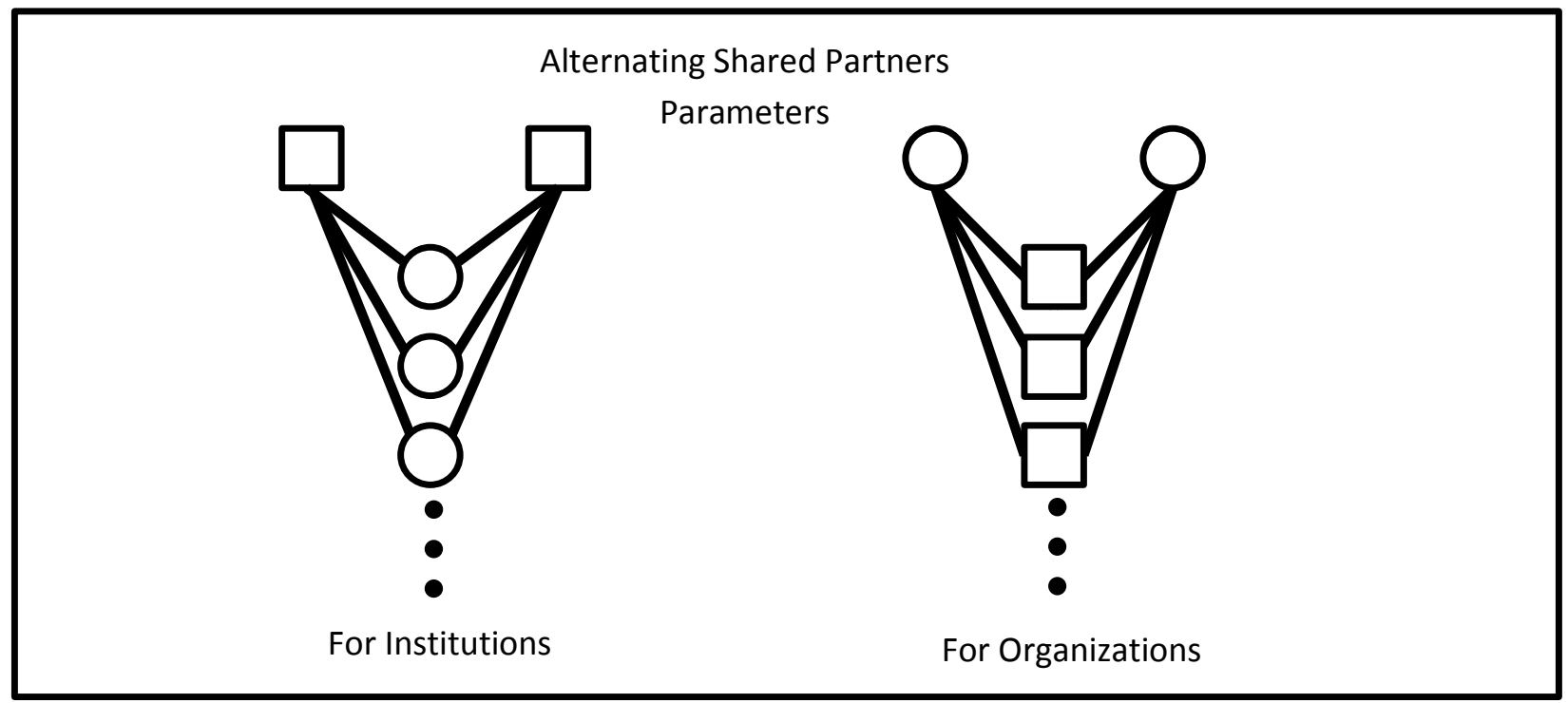

Figure 8: Shared Partner Parameters

\subsection{Simulating from ERGM models}

None of the current ERGM software contains specifications for brokerage chains with an added attribute classification. While creating these terms might be a worthwhile endeavor, the increasing complexity of the structures prompts some cause for concern about how well these models could fit even if the terms were simple to implement. The method we have chosen in this paper is to simulate from the series of nested models with lower order terms and use these simulations as a baseline model. We compare the empirical counts of brokerage to the counts for each simulated network, and thus are able to discern how much of the empirical brokerage is likely explained by these other structural forms (Jasny 2012; Mayhew 1984). 
This analysis is done in five steps. First, we fit multiple ERG models to the empirical data. We pick the one that best fits the data according to the Mahalanobis distance (Wang et al 2009). This model does not include any brokerage terms. Next, we simulate 1000 networks from the model generated. From each simulation, we identify all the brokerage chains. These are all of the chains such that two institutions are connected by a shortest path through a third institution. Once these chains are identified, they are sorted into the different brokerage categories outlined in Figure 2. Finally, these counts are compared to the empirical counts as in standard statistical hypothesis testing.

\section{Results}

We begin by examining the empirical brokerage scores grouped by institution type. These results compare the institutions to each other and addresses our first hypothesis - that Multistakeholder Partnerships broker the most of all the institution types. To answer the remaining hypotheses we turn to the results of the Exponential Random Graph Models and simulation.

\subsection{Empirical Brokerage Results}

Table 1 shows the counts of brokerage chains in the empirical data by institution type divided by the number of institutions in the network of that type. For example the average Multistakeholder Partnership brokers 59 chains coordinator chains with the same type of organizations, but 271 coordinator chains where the organizations are of different types. The final row displays the sum of the normalized counts for each brokerage chain type. 


\begin{tabular}{|c|c|c|c|c|c|c|c|c|c|}
\hline & \multicolumn{2}{|c|}{ Coordinator } & \multicolumn{2}{|c|}{$\begin{array}{r}\text { Representative/ } \\
\text { Gatekeeper }\end{array}$} & \multicolumn{2}{|r|}{ Itinerant } & \multicolumn{2}{|r|}{ Liaison } & \multirow[t]{2}{*}{ Total } \\
\hline & Same & Different & Same & Different & Same & Different & Same & Different & \\
\hline $\begin{array}{r}\text { Collaborative } \\
\text { Partnerships }\end{array}$ & 59 & 271 & 436 & 1853 & 98 & 369 & 579 & 2452 & 6117 \\
\hline Projects & 39 & 211 & 376 & 2100 & 120 & 687 & 639 & 3492 & 7664 \\
\hline Local Planning & 8 & 57 & 155 & 938 & 100 & 511 & 542 & 2674 & 4985 \\
\hline Conservancy & 1 & 6 & 27 & 137 & 19 & 135 & 78 & 739 & 1142 \\
\hline Science & 16 & 11 & 259 & 375 & 230 & 262 & 1020 & 1298 & 3471 \\
\hline Interest Groups & 1 & 1 & 29 & 75 & 49 & 111 & 279 & 625 & 1170 \\
\hline Joint Powers & 0 & 0 & 65 & 210 & 196 & 491 & 975 & 3026 & 4963 \\
\hline $\begin{array}{r}\text { Advisory } \\
\text { Committee }\end{array}$ & 0 & 3 & 16 & 338 & 89 & 367 & 473 & 2094 & 3380 \\
\hline $\begin{array}{l}\text { Regulatory } \\
\text { Permitting }\end{array}$ & 3 & 7 & 80 & 146 & 47 & 111 & 290 & 658 & 1342 \\
\hline Other & 0 & 0 & 0 & 2 & 2 & 24 & 6 & 152 & 186 \\
\hline Totals & 127 & 567 & 1443 & 6174 & 950 & 3068 & 4881 & 17210 & \\
\hline
\end{tabular}

Table 1: Normalized Empirical Brokerage Scores

These results show limited support for the first hypothesis since collaborative partnerships

broker more chains on average (the last column in Table 1 shows the total) than all the other types of institutions with the exception of Projects. The totals for each kind of brokerage chain (the bottom row in Table 1) show a generally increasing trend from left (most homogeneous) to right (most heterogeneous) with the exception of the Representative/Gatekeeper scores, showing potential support for the second hypothesis. However, to determine the significance of these counts we turn to the simulations from ERG models. 


\subsection{Comparing nested ERGM models}

Table 2 shows the ERGM results for four models: the density model, a model with the degree dispersion alternating star parameters, a model with the shared partner parameters, and a final model with both sets of structural parameters added. Each model was run with the same settings in BPnet ${ }^{2}$. These models have converged since the t-ratios are close to 0 (Robins, Pattison, et al 2007). The $4^{\text {th }}$ model, with parameters for density, degree dispersion, and shared partners, has the lowest Mahalanobis distance and therefore best describes the empirical data. We discuss the coefficients in that model and use those parameters for the subsequent simulation. We begin with the density terms for both modes (institutions and organizations) and then move to the more complex structural terms in the model.

Each density term gives the log-odds of that type of institution (or organization) having a tie above the probability of the reference group. For example, with a significant log-odds value of .703 , federal organizations are approximately twice as likely (67\%-33\%) as local organizations (the reference category) to participate in venues. ${ }^{3}$ All the institution types have fewer ties (participating organizations) than the collaborative partnership reference category, ranging from a relative probability of $30 \%$ (the 'other' category with a log-odds value of -0.784 ) to $47 \%$ (the ‘joint powers' category with a log-odds value of -0.085). Thus, although the collaborative partnerships do not lead the network in brokered chains, they do in overall number of participating organizations.

\footnotetext{
${ }^{2}$ Default parameters except we controlled for no isolates, and set the multiplication factor to 200 . This change permitted the model to wander the parameter space more before finding the local maximum (Wang et al. 2009). We also used structural 0 s to condition the model on the ties of the top 5 institutions and organization by degree. This was done to achieve better model fit as in Lubell et al 2011.

${ }^{3}$ To convert log-odds to probability, exponentiate the coefficient and divide by one plus the exponentiation.
} 
The structural terms test for the presence of different types of network properties in each mode. The star terms (Institution Stars and Organization Stars), are positive and significant for both modes (2.606 and 0.806 respectively) indicating high levels of centralization for both institutions and organizations. The shared partner terms indicate the level of clustering present in the network. Institutions have a positive and significant coefficient (0.012), whereas organizations have a negative and significant coefficient (-0.185). The lack of clustering among organizations reflects the observation from the literature that the stakeholders involved in water policy in the subject area are heavily divided.

The positive and significant coefficient for the log of the number of removed pendants indicates that those institutions that had many pendant organizations (organizations that only attended one institutional venue) are significantly more likely to have ties in the reduced data set than those institutions which didn't lose as many pendant organizations. Thus, removing the pendants did not result in a set of institutions with lower degree distributions, in fact the exact opposite. This finding suggests that there are not central organizations that we have not measured.

The ERGM results in Model 4 reveal suggest that different organizing principles are at work in the first and second modes. This part of the analysis would have been overlooked had we used a one-mode projection rather than modeling the full structure. These mechanisms would not have been captured in the Bernoulli model that Gould and Fernandez used to test for brokerage significance. In the next section, we use simulation to test whether these mechanisms alone could plausibly explain the numbers of brokerage chains observed in the empirical data. 


\begin{tabular}{|c|c|c|c|c|c|c|c|c|c|}
\hline & & \multicolumn{2}{|r|}{ Model 1} & \multicolumn{2}{|r|}{ Model 2} & \multicolumn{2}{|c|}{ Model 3} & \multicolumn{2}{|r|}{ Model 4} \\
\hline & & Estimate & t-ratio & Estimate & t-ratio & estimate & t-ratio & Estimate & t-ratio \\
\hline \multirow{5}{*}{ 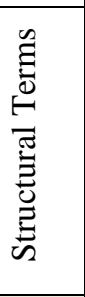 } & Edges & $-4.217^{*}$ & -0.035 & $-10.468^{*}$ & 0.064 & $-3.898 *$ & 0.061 & $-10.307 *$ & 0.081 \\
\hline & Institution Stars & & & $3.033^{*}$ & 0.068 & & & $2.606^{*}$ & 0.083 \\
\hline & Organization Stars & & & 0.261 & 0.063 & & & $0.806^{*}$ & 0.085 \\
\hline & $\begin{array}{r}\text { Institution Shared } \\
\text { Partners } \\
\end{array}$ & & & & & $0.002 *$ & 0.094 & $0.012 *$ & 0.599 \\
\hline & $\begin{array}{r}\text { Organization Shared } \\
\text { Partners } \\
\end{array}$ & & & & & $-0.199 *$ & 0.027 & $-0.185^{*}$ & 0.031 \\
\hline \multirow{13}{*}{ 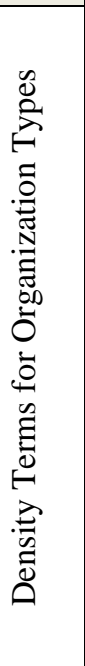 } & Federal & $0.633^{*}$ & 0.030 & $0.588^{*}$ & -0.016 & $0.874 *$ & 0.071 & $0.703 *$ & 0.001 \\
\hline & State & $0.686^{*}$ & -0.009 & $0.631 *$ & 0.061 & $0.985^{*}$ & 0.039 & $0.767 *$ & 0.025 \\
\hline & Regional & $0.845^{*}$ & 0.024 & $0.796^{*}$ & -0.035 & $1.205^{*}$ & 0.016 & $0.975^{*}$ & 0.031 \\
\hline & Special District & -0.142 & 0.008 & -0.132 & 0.068 & -0.180 & 0.059 & -0.143 & 0.047 \\
\hline & $\begin{array}{r}\text { Environmental Special } \\
\text { District }\end{array}$ & -0.096 & -0.046 & -0.095 & -0.010 & -0.126 & -0.004 & -0.111 & -0.010 \\
\hline & Environmental Group & -0.193 & -0.042 & -0.191 & -0.015 & $-0.236^{*}$ & 0.031 & $-0.214^{*}$ & -0.006 \\
\hline & Business & -0.293 & -0.017 & -0.250 & -0.061 & $-0.385^{*}$ & 0.049 & -0.259 & 0.088 \\
\hline & $\begin{array}{r}\text { Educational } \\
\text { Organization }\end{array}$ & -0.213 & -0.041 & -0.204 & -0.022 & $-0.275^{*}$ & 0.030 & $-0.229 *$ & 0.067 \\
\hline & $\begin{array}{r}\text { Multi-Stakeholder } \\
\text { Coalition }\end{array}$ & -0.355 & -0.003 & -0.327 & -0.098 & $-0.460 *$ & -0.024 & -0.354 & 0.042 \\
\hline & Recreational Group & $0.547^{*}$ & -0.021 & 0.488 & 0.003 & $0.782 *$ & 0.054 & 0.580 & 0.071 \\
\hline & Agriculture & $-0.554 *$ & -0.087 & $-0.531 *$ & 0.029 & $-0.675^{*}$ & 0.054 & $-0.571^{*}$ & -0.000 \\
\hline & Tribal & -0.524 & 0.033 & -0.491 & 0.124 & -0.611 & -0.010 & -0.439 & -0.021 \\
\hline & Other & $1.413^{*}$ & 0.029 & $1.338^{*}$ & 0.042 & $2.311^{*}$ & -0.017 & $1.969 *$ & 0.019 \\
\hline & & & & & & & & & \\
\hline \multirow{12}{*}{ 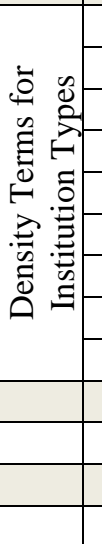 } & Local Planning & $-1.161 *$ & 0.022 & $-0.507 *$ & 0.032 & $-0.842 *$ & -0.036 & $-0.290 *$ & -0.057 \\
\hline & Science & $-0.710^{*}$ & -0.026 & $-0.650 *$ & 0.026 & $-0.502^{*}$ & 0.028 & $-0.468^{*}$ & -0.035 \\
\hline & Conservancy & $-0.664^{*}$ & -0.049 & $-0.523 *$ & -0.039 & $-0.428^{*}$ & -0.061 & $-0.339 *$ & 0.104 \\
\hline & Joint Powers & $-0.408^{*}$ & -0.003 & -0.276 & -0.008 & -0.146 & -0.055 & -0.085 & -0.020 \\
\hline & Interest Group & $-0.615^{*}$ & -0.003 & $-0.479 *$ & -0.038 & $-0.318^{*}$ & 0.030 & $-0.235^{*}$ & 0.075 \\
\hline & Advisory & $-0.450^{*}$ & 0.044 & $-0.328 *$ & -0.028 & -0.225 & 0.032 & -0.147 & -0.027 \\
\hline & Projects & $-0.792^{*}$ & 0.021 & $-0.597 *$ & -0.064 & $-0.538^{*}$ & -0.013 & $-0.421^{*}$ & 0.037 \\
\hline & Regulatory & $-0.863^{*}$ & -0.055 & $-0.649 *$ & 0.065 & $-0.547 *$ & -0.020 & $-0.391 *$ & -0.009 \\
\hline & Other & $-2.272^{*}$ & -0.142 & $-1.063 *$ & -0.010 & $-1.890 *$ & -0.117 & $-0.784^{*}$ & 0.015 \\
\hline & Log(Pendant Number) & $0.572 *$ & -0.003 & $0.443^{*}$ & 0.061 & $0.406^{*}$ & 0.073 & $0.309 *$ & 0.157 \\
\hline & & & & & & & & & \\
\hline & Mahalanobis Distance & 108.067 & & 111.249 & & 149.787 & & 105.490 & \\
\hline
\end{tabular}




\subsection{Simulated Brokerage Results}

We simulated 1000 networks from the parameter values of the sufficient statistics in Model 4. Figure 9 shows a goodness-of-fit plot for geodesic distances (shortest paths) between each pair of nodes in each of the simulated networks. The bar plot represents the distances in all the simulated networks and the stars (connected by the bolded line) are the empirical values. The

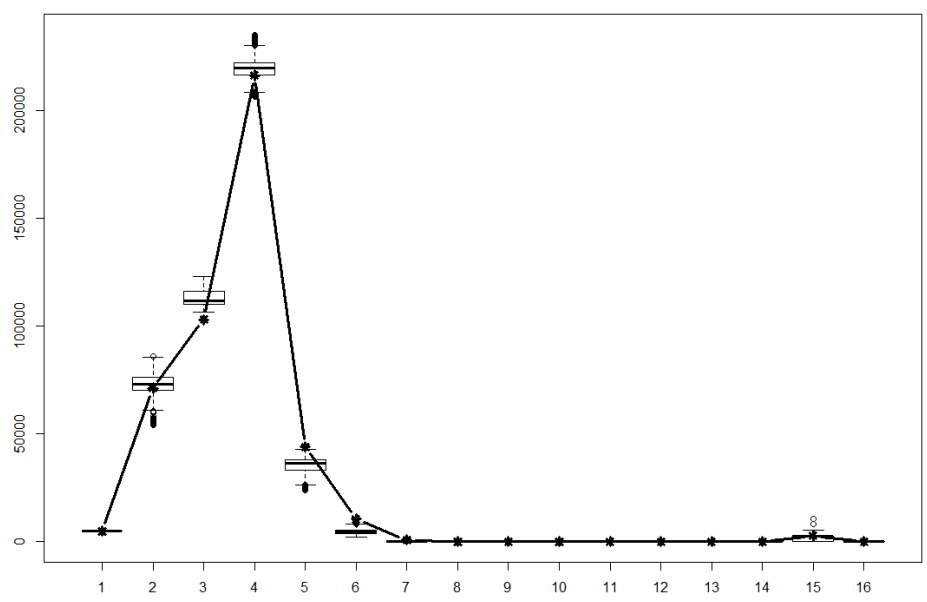

Figure 9: Goodness of Fit for Geodesic Distance

simulated data fits the empirical values reasonably well with every data point falling within the quantiles except for path lengths of three which is slightly high compared to the empirical data and paths of length five which is slightly low in comparison.

Figures 10 and 11 show how significance is calculated for each brokerage chain, and how to interpret Figure 12 (the results for each type of chain by institution type). The brokerage chains were counted for each simulation and categorized by organization and institution heterogeneity according to the configurations in Figure 2. Figure 11 shows two examples: Scientific institutions brokering two other Scientific institutions (Coordinator brokerage) between the same 
types of participating organizations (top) and different types of organizations (bottom). The histogram shows the count of this type of chain in each of the 1000 simulations, and the dotted line is the empirical value. For the brokerage chains where the organizations are of the same type, the simulated networks replicated the number of chains found empirically. This empirical count is within two standard deviations of the mean of the simulated distribution of scores, and thus is depicted by a white circle (fifth row, first column of Figure 12) which indicates nonsignificance according to Figure 10. Conversely, when brokering differing types of organizations, none of the simulated models had a lower number of such brokerage chains. As a result, this score is negatively significant at .000 and represented by a downward pointing black triangle (fifth row, second column in Figure 12). The symbols in Figure 12 are shaded according to the key in Figure 10 and sized by the relative difference between the mean of the simulations and the empirical brokerage chain count, giving an estimate of how far off the simulation is in

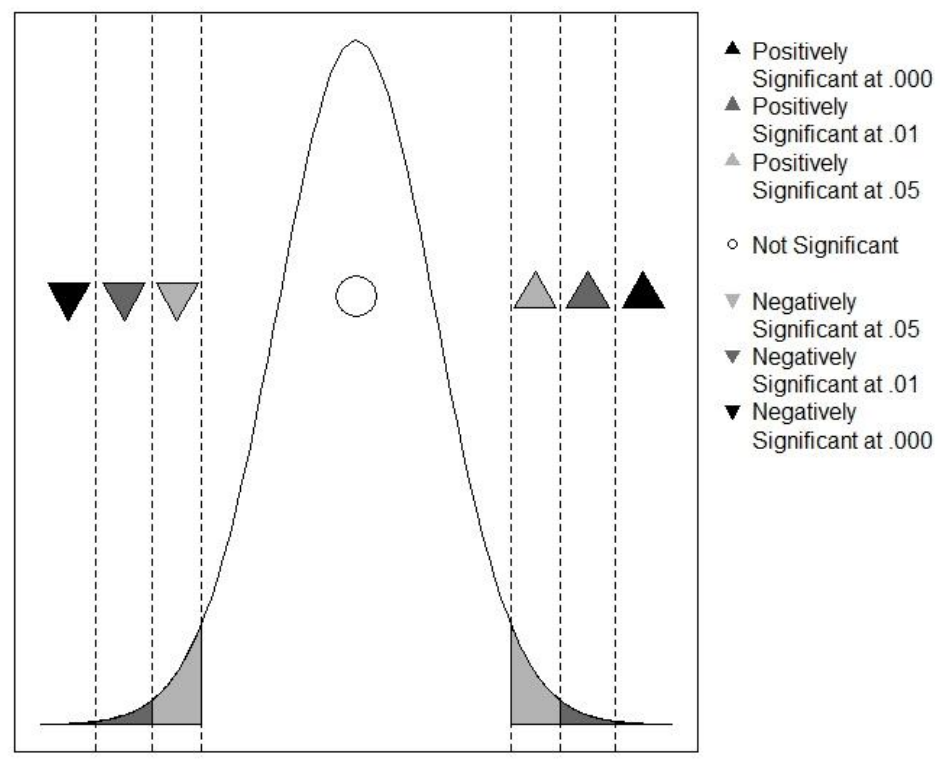

FFigure 10: Significance Key 
magnitude.
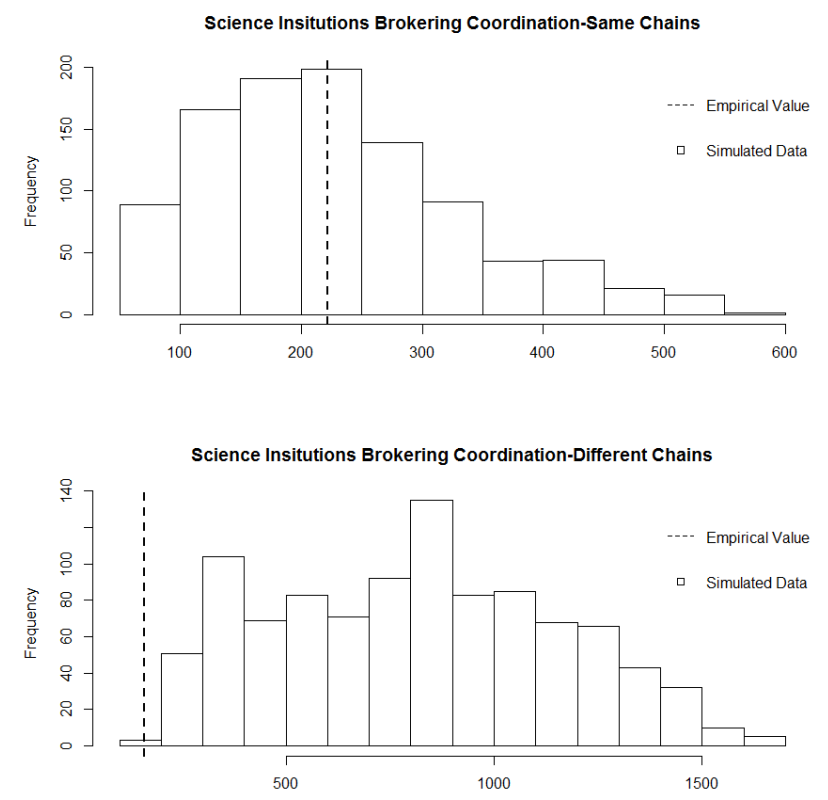

Figure 11: Two Examples of Calculating Significance

Figure 12 shows the significance of the eight types of brokerage chains for the ten institution types; 49 of the 80 tests run showed the empirical brokerage score to be positively significant when compared to the simulated distribution (all the upward pointing triangles). In 12 cases, there were significantly fewer brokerage chains than expected (the downward pointing triangles). Clearly the two mechanisms of centralization and clustering do not explain the empirical brokerage observed in the network. This finding supports our third hypothesis. There is 
something else at work beyond these two mechanisms that results in the large amount of brokerage in our empirical case.

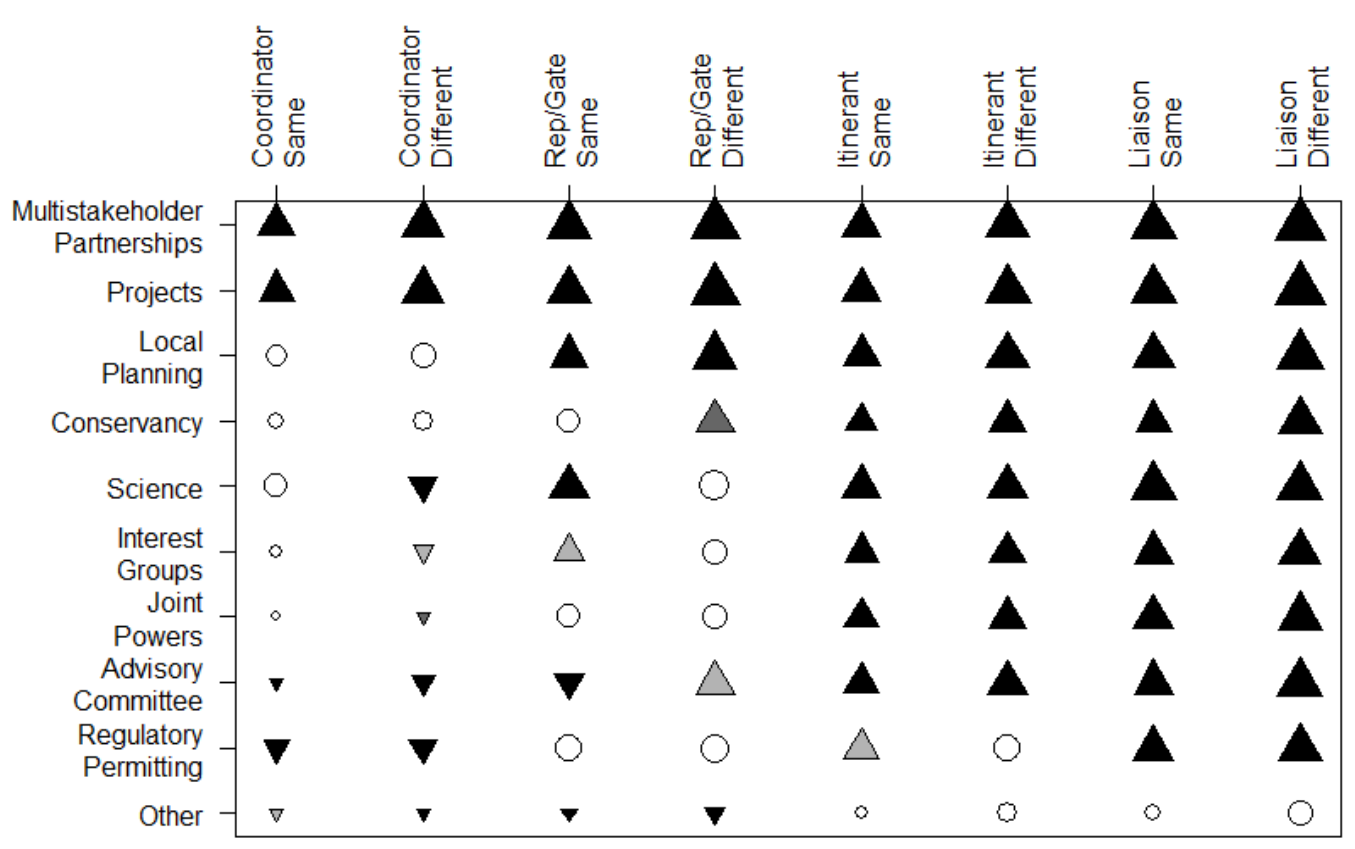

Figure 12: Significance of Brokerage Chains in Edge Model

Additionally, the findings in Figure 12 support our first two hypotheses. We see that Multistakeholder partnerships are tied with Projects for being involved in the most significant levels of brokerage. Second, heterogeneous chains are more likely to be brokered at significant rates (compared to the null model) than homogenous chains, supporting the second hypothesis.

\section{Conclusion}

This article makes methodological, theoretical, and substantive contributions to the study of brokerage in two-mode networks. On the methodological side, we show how Gould and Fernandez's conceptualization of brokerage can be expanded to two-mode brokerage chains. Brokerage chains feature a central node from first mode of the network that links two other 
nodes via links in the second mode of the network. Given the classification of nodes into different types, we provide a measure of heterogeneity in the brokerage chains. Future research in two-mode brokerage should build on this combination of structural and attribute terms. It would be useful to develop a set of ERGM terms that would follow this homogeneity/heterogeneity scale to fully parameterize the patterns seen here. Gould and Fernandez' premise that structural patterns take on entirely different meanings when colored by the attribute classes of the actors present is an important observation, the ramifications of which have not been fully developed in current network theory or methods. Instead of dividing our theory and methods into separate attribute and structural effects, we need to explore the possible interdependence of these terms.

On the theoretical side, we extend the logic of Gould and Fernandez to argue that the benefits of brokerage are highest in heterogeneous chains. In the empirical case of water governance, institutions that are involved in heterogeneous chains are expected to have more influence over decisions in the network, and higher capacity to ameliorate problems of fragmentation. As with Gould and Fernandez, we expect brokerage to be concentrated for certain types of actors and institutions. In particular, collaborative partnerships are specifically designed to mitigate fragmentation. We show that they occupy these brokerage roles at significantly higher levels than expected under different null models of random networks. We also see that as the level of heterogeneity in the chain increases, so do the number of brokerage chains (Table 1) as well as how many different types of brokerage chains have significantly high counts when compared to the baseline model (the number of positively significant chains increases as we move from left to right in Figure 12). 
The substantive contribution demonstrates the relevance of brokerage to water governance in the California Delta. A significant amount of brokerage exists in the CA Delta ecology of games that is not explained by the presence of alternative mechanisms. These brokerage activities have emerged over time as water policy actors have struggled with the fragmented policies that address complex water problems in the region. Brokerage is likely to emerge from an evolutionary process, where policy entrepreneurs identify problems of fragmentation and seek to build institutions and networks that catalyze cooperation among previously conflicting actors. To the extent these policy entrepreneurs capture the benefits of brokering institutions, and enough of the involved actors provide political support, such brokering institutions are more likely to survive in the overall system.

This argument is consistent with our empirical observation that brokerage is concentrated among the most heterogeneous types of chains, where the benefits are expected to be greatest. Brokerage is also concentrated among collaborative partnerships which have the goal of spanning various types of boundaries to increase cooperation. Hence, the observed patterns of brokerage are a sign of effective governance in the system and the benefits of the multistakeholder partnerships in combatting the issues of fragmentation. However, it is impossible to say from this research whether there is enough brokerage in the system, relative to some other type of unobserved, counterfactual institutional arrangements. Future research, most likely with longitudinal data, is necessary to further develop and test hypotheses about how these important brokerage chains arise and what policy outcomes result. Such research also needs to analyze why different actors create and participate in brokering institutions. 


\section{References}

Agneessens, Filip and Martin G. Everett. 2013. "Introduction to the special issue on advances in two-mode social networks." Social Networks 35(2).

Aldrich, Howard E.; and Herker, Diane. 1977. "Boundary Spanning Roles and Organization Structure.” Academy of Management Review 2.2.

Ansell, Chris and Alison Gash. 2007. "Collaborative Governance in Theory and Practice." Journal of Public Administration Research and Theory 18:543-571.

Berkes, Fikret. 2002. "Cross-Scale Institutional Linkages: Perspectives from the Bottom Up." In The Drama of the Commons. Elinor Ostrom, Thomas Dietz, Nives Dolšak, Paul C. Stern, Susan Stonich, and Elke U. Weber, Editors. Washington, DC: National Academy Press.

Borgatti, Stephen P.; Everett, Martin G. 1997. "Network Analysis of 2-Mode Data." Social Networks 19(3).

Brown, David. 1998. "Creating Social Capital: Nongovernmental Development Organizations and Intersectoral Problem Solving." In Private Action and the Public Good. Walter W. Powell and Elizabeth S. Clemens, Editors. Connecticut: Yale University Press.

Burt, R.S., 2001. "Structural Holes versus Network Closure as Social Capital.” In Social Capital: Theory and Research. Nan Lin, Karen Cook, and R.S. Burt, Editors. New Jersey: Transaction Publishers, 2001.

Burt, R.S., 2005. Brokerage and Closure: An Introduction to Social Capital. Oxford University Press, New York.

Butts, Carter t. 2011. "Bayesian Meta-Analysis of Social Network Data Via Conditional Uniform Graph Quantiles.” Sociological Methodology 41:257-298.

Carlsson, Lars; and Sandstrom, Annica. 2008. "Network Governance of the Commons." International Journal of the Commons. Vol 2.

Chaskin, RJ. 2001. "Organizational infrastructure and community capacity: The role of broker organizations." Research in Social Problems and Public Policy. Vol 8.

Collins-Dogrul. 2012. "Tertius Iungens Brokerage and Transnational Intersectoral Cooperation.” Organization Studies Vol 33.

Crona, Beatrice and J. Parker. 2012. "Learning in support of governance: theories, methods and a framework to assess how bridging organizations contribute to adaptive resource government." Ecology and Society Vol 17(1). 
Doreian, Patrick; and Woodard, Katherine L. 1994. "Defining and locating cores and boundaries of social networks." Social Networks Vol 16.

Fernandez, Roberto M. and Roger V. Gould. 1994. "A Dilemma of State Power: Brokerage and Influence in the National Health Policy Domain.” American Journal of Sociology, Vol 99(6).

Freeman, Linton C. 1978. "Segregation in Social Networks." Sociological Methods and Research 6:411-29.

Freeman, Linton C. 2004. The Development of Social Network Analysis: A Study in the Sociology of Science. Vancouver, BV: Empirical Press.

Friedman, Raymond A. and Joel Podolny. 1992. "Differentiation of Boundary Spanning Roles: Labor Negotiations and Implications and Role Conflict." Administrative Science Quarterly 37:28-47.

Gould, Roger V., and Roberto M. Fernandez. 1989. "Structures of Mediation: A Formal Approach to Brokerage in Transaction Networks." Sociological Methodology 19:89-126.

Hahn, Thomas; Olsson, Per; Folke, Carl; and Johansson, Kristin. 2006. "Trust-building, Knowledge Generation and Organizational Innovations: The Role of a Bridging Organization for Adaptive Comanagement of a Wetland Landscape around Kristianstad, Sweden." Human Ecology, Vol 34(4).

Heaney, Michael T. 2006. "Brokering Health Policy: Coalitions, Parties, and Interest Group Influence." Journal of Health Politics, Policy and Law. Vol 31(5).

Hobson, John A. 1884. The Evolution of Modern Capitalism: A Study of Machine Production. Londen: Allen, Uwin, and Macmillan.

Hughes, Sara and Stephanie Pincetl. 2013. "Evaluating collaborative institutions in context: the case of regional water management in southern California." Environment and Planning C:

Government and Policy Vol 31.

Jasny, Lorien. "Baseline Models for Two-Mode Social Network Data." 2012. Policy Studies Journal Vol 40(3).

Kossinets, Gueorgi. 2006. "Effects of missing data in social networks." Social Networks vol 28.

Latapy, Matthieu, Clemence Magnien and Nathalie Del Vecchio. 2008. "Basic notions for the analysis of large two-mode networks." Social Networks Vol 30.

Leach, William D and Neil W. Pelkey and Paul A. Sabatier. 2002. "Stakeholder Partnerships as Collaborative Policymaking: Evaluation Criteria Applied to Watershed Management in California and Washington." Journal of Policy Analysis and Management vol 21(4):645-670. 
Long, Norton E. 1958. "The Local Community as an Ecology of Games." The American Journal of Sociology

Lubell, Mark N. 2013. "Governing institutional complexity: the ecology of games framework." Policy Sudies Journal Vol 31(3):537-559.

Lubell, Mark N. and Lucas Lippert. 2011. "Integrated regional water management: a study of collaboration or water politics-as-usual in California, USA." International Review of Administrative Sciences Vol 77(76).

Lubell, Mark N.; Robins, Garry; and Wang, Peng. 2011. "Policy Coordination in an Ecology of Water Management Games." http://opensiuc.lib.siu.edu/pnconfs_2011/22

Lund, Jay R. 2010. Comparing futures for the Sacramento-San Joaquin Delta. Berkeley, California: University of California Press.

Manring, Susan L. 2007. "Creating and Managing Interorganizational Learning Networks To Achieve Sustainable Ecosystem Management.” Organization Environment Vol 20.

Marsden, Peter V. 1982. "Brokerage Behavior in Restricted Exchange Networks." Pp. 201-18 in Social Structure and Network Analysis, edited by Peter V. Marsden and Nan Lin. Beverly Hills, California: Sage.

Mayhew, Bruce. 1984. "Baseline Models of Sociological Phenomena." Journal of Mathematical Sociology 9 (4): 259-81.

Newman, Mark EJ. 2002. "Random graphs as models of networks." arXiv preprint condmat/0202208.

Opsahl, Tore. 2011. "Triadic Closure in Two-Mode Networks: Redefining the Global and Local Clustering Coefficients." Social Networks, doi:10.1016/j.socnet.2011.07.001.

Robins, Garry; Pattison, Philippa; and Woolcock, Jodie. 2004. "Missing data in networks: exponential random graph $\left(p^{*}\right)$ models for networks with non-respondents." Social Networks Vol 26.

Robins, Garry; Pattison, Philippa; Kalish, Yuval, and Lusher, Dean. 2007. "An introduction to exponential random graph (p*) models for social networks.” Social Networks Vol 29.

Robins, Garry; Snijders, Tom; Wang, Peng; Handcock, Mark; Pattison, Philippa. 2007. "Recent developments in exponential random graph $\left(\mathrm{p}^{*}\right)$ models for social networks." Social Networks Vol 29. 
Schneider, Mark and John Scholz and Mark Lubell and Denisa Mindruta and Matthew Edwardsen. 2003. "Building Consensual Institutions: Networks and the National Estuary Program.” American Journal of Political Science 47(1):143-158.

Scholz, John T. and Ramiro Berardo and Brad Kile. 2008. "Do Networks Solve Collective Action Problems? Credibility, Search, and Collaboration." The Journal of Politics vol 70(2).

Simpson, Edward H. 1949. "Measurement of Diversity." Nature 163:688.

Snijders, T.A., Pattison, P.E., Robins, G.L., Handcock, M., 2006. New specifications for exponential random graph models. Sociological Methodology 36, 99L 153.

Stovel, Katherine; and Shaw, Lynette. 2012. "Brokerage." Annual Review of Sociology.

Wang, Peng, Ken Sharpe, Garry L. Robins, and Philippa E. Pattison. 2009. "Exponential Random Graph (P*) Models for Affiliation Networks." Social Networks 31: 12-25.

Wang, Peng, Garry Robins, Philippa Pattison and Emmanuel Lazega. 2013. "Exponential random graph models for multilevel networks." Social Networks 35(1).

Wang, Peng, Philippa Pattison and Garry Robins. 2013. "Exponential random graph model specifications for bipartite networks-A dependence hierarchy." Social Networks 35(2). 